\title{
Motivation of cancer patients to help others and the relation between posttraumatic growth and helping
}

\author{
Weronika Trzmielewska (D) 1·A,B,C,D,E,F, Mariusz Zięba (D) ${ }^{2 \cdot E, F}$, Marta Boczkowska (DD ${ }^{3 \cdot B, D, F}$, \\ Tomasz Rak (D) 4·C, Szymon Wrześniowski (D) 4.C \\ 1: Warsaw Faculty of Psychology, SWPS University of Social Sciences and Humanities, Warsaw, Poland \\ 2: Poznan Faculty of Psychology, SWPS University of Social Sciences and Humanities, Poznan, Poland \\ 3: Department of Medical Psychology, Medical University of Lodz, Poland \\ 4: Independent researcher
}

\section{BACKGROUND}

Posttraumatic growth (PTG) is related to positive psychological changes following people's struggle with trauma. The PTG model suggests that one of its possible consequences may be higher motivation towards helping behaviours. The aim of the research was to explore the influence of cancer illness on the motivation to help others, as perceived by participants, and the mechanisms behind such behaviour.

PARTICIPANTS AND PROCEDURE

Quantitative and qualitative methods were used to explore the main motives to help others among cancer patients. The study also investigated the relation of perceived growth (PTG) and the frequency of providing help. Female cancer patients $(n=100)$ completed a Polish version of the Posttraumatic Growth Inventory and a questionnaire measuring frequency of providing help towards ill and healthy individuals. Some of the subjects $(n=29)$ were also interviewed to assess the main perceived motives to help others.

\section{RESULTS}

Positive rho Spearman correlations between PTG and the frequency of help given towards ill individuals and healthy ones were found. Based on thematic analysis four motives of helping were identified: empathy, self-enhancement, internalized standards of behaviour, searching for the sense of life.

\section{CONCLUSIONS}

This findings highlight the positive association between cancer patients' involvement in helping other cancer patients and positive life changes after experience of cancer.

\section{KEY WORDS}

cancer patients; coping with trauma; posttraumatic growth; prosocial behaviour

CORRESPONDING AUTHOR - Weronika Trzmielewska, SWPS University of Social Sciences and Humanities,

19/31 Chodakowska Str., 03-815 Warsaw, Poland, e-mail: wtrzmielewska@swps.edu.pl

AUthors' CONTRiBution - A: Study design - B: Data collection - C: Statistical analysis - D: Data interpretation .

E: Manuscript preparation · F: Literature search · G: Funds collection

TO CITE THIS ARTICLE - Trzmielewska, W., Zięba, M., Boczkowska, M., Rak, T., \& Wrześniowski, S. (2019). Motivation

of cancer patients to help others and the relation between posttraumatic growth and helping. Current Issues in

Personality Psychology, 7(3), 232-241.

RECEIVED 03.10.2018 · REVIEWED 10.05.2019 • ACCEPTED 16.05.2019 · PUBLISHED 25.06.2019 


\section{BACKGROUND}

It has been widely documented that oncological patients experience various types of clinical dysfunction (e.g., Park, 2009), but cancer can have positive as well as negative effects on psychological functioning (e.g., Cordova, 2008). Since the 1990s, therefore, research has begun to focus on personal growth in the aftermath of cancer. Reports show that between 30 and $90 \%$ of sick people have experienced various types of benefits after cancer (e.g., Stanton, Bower, \& Low, 2006).

One widely known account of personal growth in the aftermath of trauma is post-traumatic growth (PTG) theory (Calhoun \& Tedeschi, 2006, 2013; Tedeschi \& Calhoun, 1996; Tedeschi, Shakespeare-Finch, Taku, \& Calhoun, 2018). PTG is a term used to refer to positive psychological changes resulting from people's struggles with challenging circumstances. The PTG model represents the complex process of coping with trauma and consists of the following elements: pre-trauma individual differences and core beliefs about the world, characteristics of seismic events and their impact on schemata, cognitive struggles with traumatic circumstances including intrusive and deliberative ruminations, self-disclosure and social support for schema change.

According to Tedeschi, Shakespeare-Finch, Taku, and Calhoun (2018, p. 25) the process of PTG "may take various shapes, such as a spiral, going back and forth in interactions with other systems". PTG is sometimes, but not always, initiated by a traumatic event and is both a process and the outcome of a process. Growth can occur in many ways, with varying dynamics, depending on the impact of the triggering event on the person's core beliefs about the world and him or herself (Calhoun \& Tedeschi, 2013). Many types of traumatic event are thought to stimulate PTG. One of them is experiencing a life-threatening disease such as cancer (Park, 2009). The experience of being diagnosed and treated for cancer is highly stressful and potentially traumatic. Discovering that one has a life-threatening illness can be shocking and traumatic, because the diagnosis itself has a seismic impact on some patients' lives, and the course of the illness often undermines people's assumptions of invulnerability, predictability, and control (Calhoun \& Tedeschi, 2013; Casselas-Grau, Ochoa, \& Ruini, 2017; Cordova, Riba, \& Spiegel, 2017).

The extent to which oncology patients experience PTG depends on their individual assessment of how their life is threatened (e.g., Sumalla, Ochoa, \& Blanco, 2009), the intensity of their suffering (Stanton et al., 2006) and their self-blame or perception of responsibility for their illness (Park, 2009). The results of empirical research on cancer patients have generally been consistent with the theoretical concept of PTG; in other words, the more one perceives the can- cer as a threat to one's life, the greater one's suffering or self-blame, and the greater the potential for PTG in cancer patients (Stanton et al., 2006).

The evidence on the relationships between psychiatric conditions (e.g., anxiety and depression) is inconsistent (Casellas-Grau et al., 2017). The research relating PTG to illness factors (e.g. time since diagnosis and treatment, severity of disease) is also inconsistent (Casellas-Grau et al., 2017; Shand, Cowlishaw, Brooker, Burney, \& Ricciardelli, 2015; Morris, Shakespeare-Finch, \& Scott, 2012; Stanton et al., 2006). According to Tedeschi et al. (2018) there are two factors responsible for the inconsistency of the relationship between time since trauma and PTG: individual variability in the trajectories of PTG processes and problems with measurement of time since the traumatic event. This latter is particularly pertinent in cases such as cancer, where there is some uncertainty as to when the trauma starts, from the perspective of the patient - is it with the preliminary diagnosis of a life-threatening illness, when the diagnosis is confirmed, or when treatment starts? The time between diagnosis and assessment of PTG should be taken into account in investigations.

Data from many recent studies on conditions that promote PTG in oncological patients have also pointed to the importance of non-cancer-related characteristics, such as optimism, spirituality, positive coping style, social support and emotional and cognitive processing (which are positively associated with PTG; Casellas-Grau et al., 2017; Morris et al., 2012; Shand et al., 2015).

PTG outcomes are usually assessed in five domains: personal strength (increased sense of selfreliance, strength and confidence), relating to others (relationships are perceived as improved, positive changes in one's attitude or behaviours towards others), new possibilities (development of new interests and activities, discovery of new possibilities and life goals), appreciation of life (recognition and enjoyment of things that life can offer, appreciation of post-trauma life as a second chance) and spiritual and existential change (increased involvement in spiritual life, engagement with existential or religious matters). Some research indicates that different types of traumatic event may lead to PTG in different domains, but usually PTG manifests in these five areas (Tedeschi et al., 2018).

Human responses to trauma can be very complex and multi-faceted and PTG is only one aspect of the post-traumatic outcome. In recent years some researchers (e.g., Baker, Kelly, Calhoun, Cann, \& Tedeschi, 2008; Cann, Calhoun, Tedeschi, \& Solomon, 2010) have begun to be interested in the fact that trauma may also produce negative changes in beliefs in the same five areas where PTG is typically observed. Both PTG and post-traumatic depreciation (PTD) can co-exist (Kroemeke, Bargiel-Matusiewicz, 
\& Kalamarz, 2017; Zięba, Wiecheć, Biegańska-Banaś, \& Mieleszczenko-Kowszewicz, 2019). Some studies suggest that PTG may also co-exist with other negative post-trauma outcomes, such as post-traumatic stress disorder (PTSD; Shakespeare-Finch \& de Dassel, 2009; Zoellner \& Maercker, 2006).

PTG could be related to some positive outcomes, such as happiness, positive emotions and eudaimonic wellbeing, but there are no direct relationships between PTG and these outcomes (Tedeschi et al., 2018). According to the PTG model (Calhoun \& Tedeschi, 2013), PTG can increase wellbeing and adjustment because PTG leads to greater wisdom and the construction of a more complex life narrative.

Changes in all five PTG domains have been reported by cancer patients (Ruini \& Vescovelli, 2013; Stanton et al., 2006). Increased awareness of the danger to life may enhance people's appreciation of life (e.g., Cordova, 2008). Some cancer patients have declared after their encounter with cancer that they discovered in themselves an inner strength they did not know they had (e.g., Hefferon, Grealy, \& Mutrie, 2009). Cancer patients have also reported strengthened relationships, which is attributed to re-evaluation of relationships with others as a result of interpersonal experiences during illness (e.g., Stanton et al., 2006).

It has also been noted that people who have experienced life-threatening diseases often choose to help others (Janoff-Bulman, 2006), especially those who are ill (Cohen \& Numa, 2011). Increased motivation to help others appears to be one of the transformations that may occur in the aftermath of cancer (e.g., Chorzela, 2013; Coward \& Kahn, 2005; Morris et al., 2012). It has been observed that the more often individuals experience traumatic events, the greater their tendency to help others (Frazier et al., 2013). Calhoun and Tedeschi (2013) attributed the growth in prosocial behaviour following trauma to an increase in empathy and compassion. The giving of help in the aftermath of personal experience of stressful events may take the form of small acts of kindness, but may include tasks that involve a full-time commitment. Tedeschi, Park, and Calhoun (1998) emphasised that the gift of trauma is an affective understanding of events that is exclusive to patients. They noted that patients often develop a strong desire to share this gift of knowledge with others who have experienced or are experiencing similar stress.

Schaefer and Moos (2008) claimed that it is the loss of independent functioning during illness that activates or increases sensitivity to other people and a willingness to support them. Similarly, Vollhardt (2009) argued that personal, unintentional suffering - such as severe illness - prompts people to direct help towards those suffering in a similar way. In other words, the greater the similarity between the experiences of a potential giver and receiver of help, the greater the readiness of the former to help the lat- ter. The author (Vollhardt, 2009) noted that prosocial behaviour can be activated by a collective sense of suffering or the perception that suffering is universal. She also claimed that in terms of health problems, the often frequent motivations for giving help to others are: seeking to make sense of life through such prosocial behaviour; identifying with those who suffer; and an increased level of compassion, empathy, and altruism. These findings are consistent with those of other researchers (e.g., Arman \& Rehnsfeldt, 2002; Cohen \& Numa, 2011; Morris et al., 2012).

Similarly, another study found that cancer patients reported that the illness had increased their ability to empathise with and help others; they also declared that they engaged in more voluntary work (i.e., helping cancer patients) than they had before their illness (Chorzela, 2013). In another study (Morris et al., 2012) participants reported experiences of PTG. Qualitative changes ranged from a deepening in understanding of others' experiences to the carrying out of supportive acts. Research has shown that experiencing cancer not only increases people's empathy and compassion for fellow cancer patients, but also increases their empathy with humanity in general (Arman \& Backman, 2007).

\section{RATIONALE AND AIMS OF THE STUDY}

Although several studies have shown that cancer patients report PTG, more studies are needed to determine the relationship between experience of cancer, PTG and helping behaviour. In addition, more research is needed to improve understanding of the mechanisms that underlie the increase in helping behaviour in people who have survived a traumatic illness. The aim of this study was to investigate the relationship between perceived PTG and willingness to help others in the aftermath of cancer. Thus, our hypotheses were:

H1. PTG is positively associated with the frequency with which one helps others (hereafter helping frequency).

$\mathrm{H} 2$. Helping frequency is more strongly positively associated with change in the relating to others domain than with the change in the other domains of PTG.

A further purpose of the study was to identify what people perceived to be their main motives for helping others and to compare the importance of empathy with other motives.

\section{PARTICIPANTS AND PROCEDURE}

\section{SAMPLE SIZE}

Power analysis was used to estimate the sample size needed. We assumed the results would be satisfactory with $\alpha=.05$ and power $\alpha=.80$ thresholds with 
a predicted correlation higher than .30 in the population. The analysis showed that a sample of between 83 and 88 individuals would be needed for the correlation comparison test, and about 30-35 participants to obtain a medium effect size for comparisons for the dependent data test.

\section{PARTICIPANTS AND METHODS}

The participants were 100 female cancer patients (aged 21 to 83 years, $M=54.75, S D=12.95)$. More detailed information about the participants is provided in Table 1 .

Ethical approval for the study was obtained from the Ethics Board of the SWPS University of Social Sciences and Humanities. The inclusion criteria were as follows: female; aged over 18 years; diagnosed with cancer (other than brain tumours) at least six months previously; completed intensive treatment (chemotherapy or radiotherapy) at least six months ago. Participants were recruited through snowball sampling, with the assistance of non-medical organisations supporting people diagnosed with cancer, first "Amazons" ( $n=62$; women affected by breast cancer), and second "Psyche-Soma-Polis" ( $n=38$; people affected by any cancer).

Data were collected at the venues of both the organisations involved in recruitment. The researcher met all participants individually. First, the participant was given information about the general purpose of the study and completed a consent form. Next the participant completed questionnaires measuring PTG and helping frequency. Both questionnaires were self-administered. Some of the participants ( $n=29)$ were randomly selected to be interviewed about their main motives for helping others. Interviews lasted 20-40 minutes and were recorded, transcribed and analysed. About a fifth of the people invited to participate in the study (18-20\%) refused; we did not ask why.

Table 1

Patients' sociodemographic data

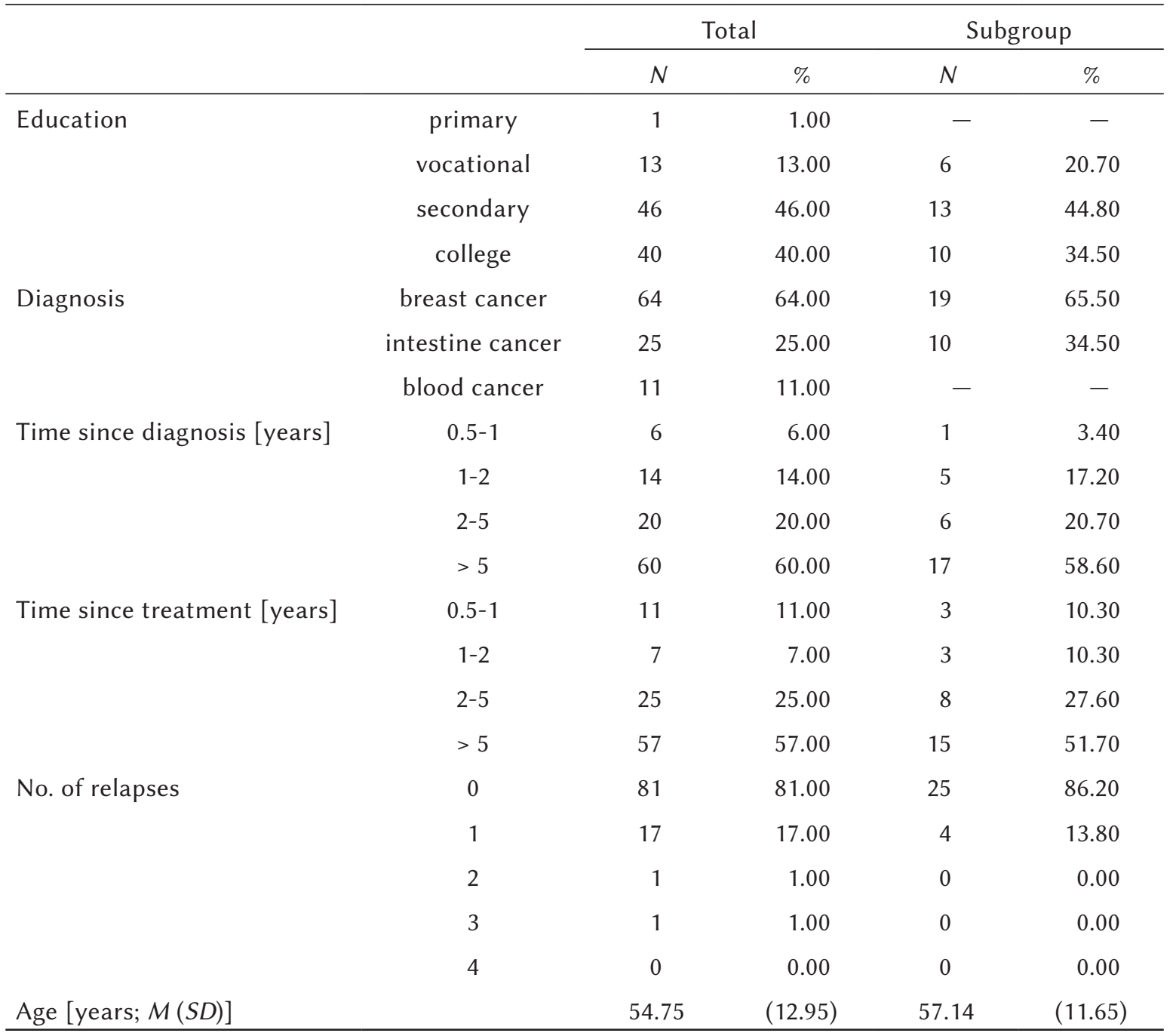




\section{QUANTITATIVE MATERIALS}

Post-traumatic growth. Perceived PTG was measured with the Polish version (IPR; Ogińska-Bulik \& Juczyński, 2010) of the Post-Traumatic Growth Inventory (PTGI; Tedeschi \& Calhoun, 1996). The original PTGI assesses five factors: relating to others; new possibilities; personal strength; spiritual changes; appreciation of life. The Polish inventory consists of the same 21 items, but confirmatory factor analysis suggested that it has four factors: relating to others, personal strength, appreciation of life and spiritual changes. Responses are given using a five-point scale from 0 (no change) to 5 (a lot of change). Internal reliability, measured as Cronbach's $\alpha$, was .88 (personal strength: $\alpha=.86$; relating to others: $\alpha=.82$; appreciation of life: $\alpha=.83$; spiritual change: $\alpha=.66$ ).

Helping frequency. The frequency with which participants provided help was measured as the average time per week spent on helping. Participants were asked questions about the amount of time they spent on activities: relaxing alone, relaxing with family, relaxing with friends, relaxing with strangers, physical exercise, taking care of their health, helping sick relatives, helping sick non-relatives, helping healthy relatives and helping healthy non-relatives. Responses were given using an 11-point scale ( 0 to $\geq 10$ hours per week). The variables of interest were average time spent helping sick people (relatives and non-relatives) and average time spent helping healthy people (relatives and non-relatives); the other questions acted as a buffer.

\section{QUALITATIVE MATERIALS}

Helping behaviour. Semi-structured interviews were used to assess helping behaviour. Participants were interviewed individually and asked their most frequent reasons for helping other people. They were asked how they felt when helping other people.

\section{ANALYSIS}

Statistical analysis. The analysis was performed with SPSS 25.0.

Analysis of interviews. Thematic analysis was carried out: data were coded in terms of topics and categories (Braun \& Clark, 2006). The aim was to identify the main themes in the participants' responses. The first stage of analysis consisted of reading the interview transcripts several times to become familiar with the answers. Next, notes were made on participants' answers. The third step consisted of developing a code distinguishing between the main categories. The fourth step involved refining this code and defining further divisions between categories. The fifth step consisted of re-analysing the data to check the suitability of the categories and the final step was to order the categories.

\section{RESULTS}

\section{ANALYSIS OF INTERVIEWS}

The following four categories of motivation for providing help were distinguished: care and support (subcategory: compassion, gratefulness); strengthening of self (subcategories: strengthening of self through downward comparison; strengthening of self through identification with others), commitment (subcategories: avoiding inevitable, moral norms and values) and searching for sense.

The care and support motive includes the desire to help to others, a desire for integration and unity and deepening of relationships and a desire to collaborate with recipients of help. Such motivation is revealed in the response of Participant 28: "If only I could do something, I'd do it with pleasure. I think that it'd be wonderful if people, if everyone could look at another person, and think what good they could do from their hearts". The compassion motive is related to a feeling of compassion for people in need and a sense of empathy with them. An example of the compassion motive for helping was provided by Participant 6: "I have experienced [cancer] myself, and I know how hard it was, and I can understand what the other person feels. I want to help so that the other person feels better". The gratefulness motive includes helping because one appreciates the help that one received from others and the spontaneous acts of kindness or generosity that one benefited from during one's own illness. In this case helping brings feelings of joy and fulfilment. This motivation is illustrated in the response of Participant 30: "After the surgery, I was approached by a girl, a volunteer"; she talked about herself with a smile. Later she came again, told me more about what I should do, and that I should not worry, because I would live. She gave me so much strength that I thought to myself that I really wanted to be like her. The strengthening of self motive covers helping behaviour aimed at regaining control or enhancing one's sense of agency, competence or power. An example of such motivation can be seen in the response of Participant 4: "[Providing help to others] gives me so much satisfaction and strength. I feel that I'm doing something important. Because after my illness I had this feeling of irreversible loss and hopelessness, and now I think that helping other people in this way fills in that gap”. The strengthening of self through downward comparison includes self-appreciation activities - that is, helping people in a worse situation than oneself or people one perceives as weaker than oneself. An example of this kind of motivation can be seen in the response of Participant 18: 
"I thought that I wouldn't be coming to the club anymore, but that would mean that I'd automatically give up visiting the women in the hospital and that was something I couldn't stop doing. Not because of me, but because of the women that I know are waiting for us. Nobody told me that [after cancer] there would be some restrictions on what I could do, truly, we are needed". The one direct reason for helping people in the strengthening of self through identification with others motive is feels a need to be close to other people and to create bonds with other people. An example of such motivation is apparent in the response of Participant 1: "No one else will understand us the way we understand ourselves [people with cancer]; there's this feeling of solidarity, a bond made during our talks about the illness, even though we haven't known one another for too long".

The commitment motive involves being motivated to help others in order to conform with social norms. An example of this kind of motivation can be seen in the response of Participant 24: "This [helping others] is necessary and I think that if someone helped me before, why can't I help someone now? Because somebody helped me, I should help someone else”. The avoiding inevitable motive is related to helping people in the expectation of receiving a reward from some higher power (e.g. God). An example of this type of motivation can be seen in the response of Participant 30: "My first thought was that when I was better, I'd do the same as she [a volunteer] was doing, that I'd go to the hospital. It was the way I decided to give something in return... [I was saying] no, God, please let me live for a bit longer and I'll start helping". The values and moral norms motive covers help that is given out of commitment to a moral system, philosophy of life or religion. An example of such motivation may be found in the response of Participant 15: "My mother kept telling me 'you ought to help other people, because you never know when you may need help yourself,' and somehow it's stayed with me since I was a child. Now I realise that that's the way people should live, that it's essential to me".

The final motive identified from the participants' responses was the searching for sense motive, which involves helping others in order to make sense, or find meaning in life. In this case helping others is a means of making sense of one's traumatic experience. An example of such motivation is revealed in the response of Participant 1: "I need to know that there's some sense in it, that there was some meaning in my experience [of cancer], that because of my experience I can give someone something; that it didn't happen in vain".

The responses were scored on a four-point scale according to the extent to which they illustrated each of four distinct categories of changes in helping behaviour - from 0 (the motive has not been revealed) to 3 (the motive has been revealed).

\section{QUANTITATIVE ANALYSIS}

Steiger's $t$-test was used to test the difference between correlations. The frequency with which sick people were helped was more strongly correlated with personal strength $(r=.51, p<.001)$ than with $r e$ lating to others $(r=.28, p<.01)$. This was the only pair of correlations that were different from each other $(z=2.44, p<.01)$. Frequency with which healthy

Table 2

Mean values, standard deviations and Spearman-rho correlations among variables $(n=100)$

\begin{tabular}{|c|c|c|c|c|c|c|c|c|}
\hline Category & $M$ & $S D$ & 1 & 2 & 3 & 4 & 5 & 6 \\
\hline 1. PTG & 74.43 & 16.91 & - & & & & & \\
\hline $\begin{array}{l}\text { 2. PTG - personal } \\
\text { strength }\end{array}$ & 27.67 & 7.46 & $.90^{* * *}$ & - & & & & \\
\hline $\begin{array}{l}\text { 3. PTG - relating } \\
\text { to others }\end{array}$ & 25.40 & 6.29 & $.71^{* * *}$ & $.45^{* * *}$ & - & & & \\
\hline $\begin{array}{l}\text { 4. PTG - appreciation } \\
\text { of life }\end{array}$ & 12.56 & 3.15 & $.52^{* * *}$ & $.55^{* * *}$ & $.26^{* *}$ & - & & \\
\hline $\begin{array}{l}\text { 5. PTG - spiritual } \\
\text { changes }\end{array}$ & 5.50 & 2.96 & $.55^{* * *}$ & $.39 * * *$ & $.29^{* *}$ & .06 & - & \\
\hline $\begin{array}{l}\text { Helping healthy } \\
\text { people }\end{array}$ & 4.47 & 3.78 & $.32^{* * *}$ & $.38^{* * *}$ & .16 & $.31^{* *}$ & .01 & - \\
\hline 7. Helping ill people & 3.48 & 3.90 & $.44^{* * *}$ & $.51^{* * *}$ & .16 & $.22^{*}$ & $.22^{*}$ & $.57^{* * *}$ \\
\hline
\end{tabular}

Note. To avoid type I error, a Bonferroni correction was conducted. To determine whether any of 6 pairs of correlations is statistically significant, the $p$-value must be $p<.008 ;{ }^{*} p<.05 ;{ }^{* *} p<.01 ;{ }^{* * *} p<.001$. 
Table 3

Mean values and Wilcoxon signed-ranks test - category of motives of providing help $(n=29)$

\begin{tabular}{lcccc}
\hline Category & Mean & Mean rank & Wilcoxon $Z$ & Asymp. $p$ \\
\hline Care and support & .74 & 9.64 & 2.16 & .030 \\
Strengthening of self & .40 & 13.03 & 3.82 & .001 \\
Care and support & .74 & 7.88 & & 3.57 \\
Commitment & .14 & 15.07 & & .001 \\
Care and support & .74 & 17.83 & 2.66 & .008 \\
Searching for sense & .10 & 14.67 & & .002 \\
Strengthening of self & .40 & 8.50 & 3.17 & .667 \\
Commitment & .14 & 9.70 & & \\
Strengthening of self & .40 & 11.00 & & \\
Searching for sense & .10 & 8.88 & 5.00 & \\
Commitment & .14 & 4.20 & & \\
Searching for sense & .10 & & & \\
\hline
\end{tabular}

Note. To avoid type I error, a Bonferroni correction was conducted. To determine whether any of 6 pairs is statistically significant, the $p$-value must be $p<.008$. After Bonferroni correction the Care and support category was found to be significantly higher than the level of Commitment, and Searching for sense category.

people were helped was not correlated with relating to others $(r=.16, p=.31)$. Table 2 displays the correlations between PTG and helping frequency.

The Friedman test was used to evaluate differences in four main categories of helping motives. There was an overall difference, $\chi^{2}(3,29)=35.30, p=.001$. Wilcoxon signed-ranks tests were performed to determine which categories differed. Table 3 displays the post hoc analysis.

The level of Care and support category was significantly higher than the level of Strengthening of self; Commitment, and Searching for sense category.

\section{DISCUSSION}

The high levels of reported PTG are in line with earlier empirical data showing that PTG is common in individuals who experience cancer (Casellas-Grau et al., 2017; Morris et al., 2012; Shand et al., 2015). Moreover, our findings revealed a positive association between PTG and helping frequency, but because the relationship between helping frequency and PTG in cancer patients (both measured on a quantitative scale) does not appear to have been investigated before we were unable to compare our results with other findings.

A cross-sectional study by Cohen and Numa (2011) assessed the relationships between PTG and volunteering activity in women who had completed active treatment for cancer at least three years previously (the participants were enrolled in organisations supporting people with oncological illness). They found that women who volunteered reported a high level of PTG, but they did not control the number of hours spent or forms of help.

It is likely that there is a bidirectional relationship between perceived PTG and helping frequency such that helping other people can be a consequence of adaptation to trauma and should be considered together with other areas of PTG as to its behavioural outcomes (e.g., Morris et al., 2012). Morris, Shakespeare-Finch, and Scott (2012) assessed PTG from participants' narratives of their cancer experience. They identified PTG in the form of increased compassion towards other people suffering from a serious illness. The form this took ranged from a deeper understanding of other's experiences to supportive acts (e.g., Morris et al., 2012, p. 752: "Participant no. 223: I am a member of the Breast Cancer Network, and I can offer advice and help to other women"). Similarly, a qualitative study by Chorzela (2013) found that people who had experienced cancer at least five years previously reported positive changes in the field of helping others (e.g., engaging in volunteering for people with cancer). On the other hand, help can contribute to the PTG of the giver. Helping other people provides opportunities for social contact and sharing of emotions (Cohen \& Numa, 2011).

Unlike other researchers (e.g., Calhoun \& Tedeschi, 2013) we found that the frequency with which participants helped sick people was more strongly positively related to personal strength than to the relating to others domain of PTG. Participants reported that after experiencing cancer they started to 
believe that they would be particularly well placed to support people in need. They often perceived their role to be that of a competent advisor or expert companion, that is, they saw themselves as able truly to understand the situation of people in need (Calhoun \& Tedeschi, 2006). It is possible, therefore, that an increased sense of personal strength determines helping behaviour. We measured helping behaviour (the time spent supporting other people) rather than attitudes towards sick people. It is possible that former patients' willingness to help others is affected by post-traumatic changes in how they relate to others and in perceived personal strength, but if one is going to act on this willingness and actually take action to help others one must be convinced that one has the capacity to do so.

It is worth noting that participants mentioned two general categories of motives in relation to helping behaviour. The first category consisted of motives based on feeling empathy for potential recipients of one's help or gratitude for the support one had received oneself and the second category related to a desire to help others as a way of increasing one's own strength. The two categories seem to involve different psychological mechanisms. The motive to help others as a way of reciprocating the care and support one received oneself or making a return for one's good fortune in having recovered is one of the most frequently observed impulses amongst cancer patients who become involved in helping other people (Ruini \& Vescovelli, 2013). It is similar to helping people out of compassion and empathy, because one feels one's personal experience enables one to understand their perspective (Morris et al., 2012).

Calhoun and Tedeschi (2006) asserted that helping people in similarly difficult circumstances may be therapeutic for people who have experienced trauma, perhaps because of the opportunity for downward comparison, i.e. the helpers' sense of their own strength is enhanced by the juxtaposition of their current situation with that of people struggling with the same difficulties they experienced. It seems that these two separate categories of motivation are consistent with the division of helping behaviour into altruism-motivated and egoism-motivated helping (Batson \& Shaw, 1991). In order to improve understanding of how the trauma of experiencing cancer influences engagement in helping behaviour and the nature of the help offered, future research should focus on whether and how these variables are related to the helper's primary motivation (altruistic or egoistic) for helping. Longitudinal research would enable assessment of how helpers' motivation and the effects of helping on the helper change over time.

Our research has some limitations. First, the cross-sectional design means we cannot determine the direction of the relationships observed. Second, the results can only be generalised to one specific category of trauma, the experience of cancer, and to one population, female cancer patients. The generalisability of the findings is further limited to the Polish context, as the study was carried out in Poland, with Polish cancer patients. It is also worth adding that all participants were enrolled in organisations that help people affected by cancer and further research in more diverse samples (people who have experienced other forms of trauma, men as well as women, other nationalities) is necessary.

Another limitation is the limited variation in length of time since diagnosis and treatment. Our sample excluded cancer patients in the early stages of coping with the disease (patients were only eligible to participate if they had completed invasive treatment at least six months previously). It is worth considering whether and why patients' readiness to help other patients changes over time. Various factors might influence the trajectory of readiness to help, the nature of the patient's treatment and changes in the patient's life situation and perception of his or her cancer experience. Furthermore, there is the case of patients who have suspended or ended their professional work due to their cancer and therefore have more time. A qualitative, longitudinal by Coward and Kahn (2005) examined changes in perception of self and behaviour in women diagnosed with cancer from one month until 14 months after. They found that in the early stages of illness (1-5 months after diagnosis) women often recognised cancer as a threat to their health and life; later (5-9 months after diagnosis) they often bonded with other people affected by cancer (to increase knowledge of cancer or gain social support, and later still (9-14 months after diagnosis) they mentioned using their own cancer experiences to help others. Coward and Kahn noted that some of the participants used altruistic activities to give meaning to their own cancer experience. In future studies it would be worthwhile to investigate the influence of time since cancer diagnosis and treatment on helping behaviour and PTG.

Another limitation is that our study explored helping as the result of personal experience of cancer. Participants were asked directly whether had chosen to help other people as a direct consequence of their own cancer. This is why the study used two forms of measurement. It must be noted, however, that the use of a four-item measure also limited our assessment of the frequency of helping. More research using observational data on helping behaviour rather than self-reports is needed to determine whether experience of cancer actually increases helping behaviour. It is worth noting that we did not compare the helping frequencies of people who had experienced cancer and those who had not, so it is not possible to determine whether people who have experienced cancer are more likely to offer help than people who have not. 
Finally, future studies should use more advanced statistical analyses (e.g., hierarchical regression, structural equation modelling) and include potential mediators of the relationship between exposure to trauma and helping other than PTG or empathy (e.g., variables related to self-perception, such as self-esteem, and variables related to perceptions of others, such as interdependent and independent self; Markus \& Kitayama, 1991). Our participants frequently mentioned that their experience of cancer had changed their sense of their personal strength and courage and these changes may have influenced their helping behaviour. These participants openly stated that before their cancer they had avoided helping others out of shyness, whereas after experiencing cancer they found they had the courage to offer help.

\section{CONCLUSIONS}

The results should be of interest to practitioners. Many participants believed that their empathy, compassion and engagement in helping had increased as a result of their illness. These changes were to a large extent specific to their relationship to other cancer patients: they felt competent to help fellow cancer patients and felt they understood the situation and needs of cancer patients because of their own experience of the illness. We recommend that medical centres actively recruit and train cancer patients to offer voluntary support to oncological patients. We also found that helping was associated with increased personal strength, which is one of the ways in which PTG manifests. Regardless of causality (does patients' new-found strength prompt them to volunteer help or does helping others increase their perception of their own strength?), we find it beneficial to increase cancer patients' feelings of their self-efficacy. Training programmes and social support groups for cancer patients might help them to build an identity not just as people who have coped or continue to cope with cancer, but as people who can use their personal experience of cancer to help others.

\section{References}

Arman, M., \& Backman, M. (2007). A longitudinal study on women's experiences of life with breast cancer in anthroposophical (complementary) and conventional care. European Journal of Cancer Care, 16, 444-450.

Arman, M., \& Rehnsfeldt, A. (2002). Living with breast cancer - a challenge to expansive and creative forces. European Journal of Cancer Care, 11, 290-296.

Baker, J., Kelly, C., Calhoun, L., Cann, A., \& Tedeschi, R. (2008). An examination of posttraumatic growth and posttraumatic depreciation: Two exploratory studies. Journal of Loss \& Trauma, 13, 450-465. https://doi.org/10.1080/15325020802171367

Batson, C. D., \& Shaw, L. L. (1991). Evidence for altruism: Toward a pluralism of prosocial motives. Psychological Inquiry, 2, 107-122. https://doi.org/ 10.1207/s15327965pli0202_1

Braun, V., \& Clarke, V. (2006). Using thematic analysis in psychology. Qualitative Research in Psychology, 3, 77-101. https://doi.org/10.1191/1478088706qp063oa

Calhoun, L. G., \& Tedeschi, R. G. (2006). The foundations of posttraumatic growth: An expanded framework. In L. G. Calhoun \& R. G. Tedeschi (Eds.), Handbook of posttraumatic growth: research and practice (pp. 17-37). Mahwah, NJ: Lawrence Erlbaum Associates Publishers.

Calhoun, L. G., \& Tedeschi, R. G. (2013). Posttraumatic growth in clinical practice. New York: Routledge/ Taylor \& Francis Group.

Cann, A., Calhoun, L., Tedeschi, R., \& Solomon, D. (2010). Posttraumatic growth and depreciation as independent experiences and predictors of well-being. Journal of Loss \& Trauma, 15, 151-166. https://doi.org/10.1080/15325020903375826

Casellas-Grau, A., Ochoa, C., \& Ruini, C. (2017). Psychological and clinical correlates of posttraumatic growth in cancer: A systematic and critical review. Psycho-Oncology, 26, 2007-2018. https://doi. org/10.1002/pon.4426

Chorzela, M. (2013). Doświadczenie choroby nowotworowej jako źródło pozytywnych zmian osobowości [Malignant disease experience as a source of positive changes in personality]. Psychoonkologia, 1, 23-31.

Cohen, M., \& Numa, M. (2011). Posttraumatic growth in breast cancer survivors: a comparison of volunteers and non-volunteers. Psycho-Oncology, 20, 69-76. https://doi.org/10.1002/pon.1709

Cordova, M. J. (2008). Facilitating posttraumatic growth following cancer. In S. Joseph \& P. A. Linley (Eds.), Trauma, recovery, and growth (pp. 185-206). Hoboken, NJ: Wiley.

Cordova, M. J., Riba, M. B., \& Spiegel, D. (2017). Posttraumatic stress disorder and cancer. Lancet Psychiatry, 4, 330-338. https://doi.org/10.1016/S22150366(17)30014-7

Coward, D. D., \& Kahn, R. N. (2005). Transcending breast cancer. Making meaning from diagnosis and treatment. Journal of Holistic Nursing, 20, 264283. https://doi.org/10.1177/0898010105277649

Frazier, P., Greer, C., Gabrielsen, S., Tennen, H., Park, C., \& Tomich, P. (2013). The relation between trauma exposure and prosocial behaviour. Psychological Trauma: Theory, Research, Practice, and Policy, 5, 286-294. https://doi.org/10.1037/a0027255

Hefferon, K., Grealy, M., \& Mutrie, N. (2009). Posttraumatic growth and life threatening physical illness: A systematic review of the qualitative literature. British Journal of Health Psychology, 14, 343-378. https://doi.org/10.1348/135910708X332936 
Janoff-Bulman, R. (2006). Schema-change perspectives on posttraumatic growth. In L. G. Calhoun \& R. G. Tedeschi (Eds.), Handbook of posttraumatic growth: research and practice (pp. 81-100). Mahwah, NJ: Lawrence Erlbaum Associates Publishers.

Kroemeke, A., Bargiel-Matusiewicz, K., \& Kalamarz, M. (2017). Mixed psychological changes following mastectomy: Unique predictors and heterogeneity of post-traumatic growth and post-traumatic depreciation. Frontiers in Psychology, 8, 1245. https://doi. org/10.3389/fpsyg.2017.01245

Markus, H. R., \& Kitayama, S. (1991). Culture and the self: Implications for cognition, emotion, and motivation. Psychological Review, 98, 224-253. https:// doi.org/10.1037/0033-295X.98.2.224

Morris, B. A, Shakespeare-Finch, J., \& Scott, J. L. (2012). Post-traumatic growth after cancer: the importance of health-related benefits and newfound compassion for others. Support Care Cancer, 20, 749-756. https://doi.org/10.1007/s00520-011-1143-7

Ogińska-Bulik, N., \& Juczyński, Z. (2010). Potraumatyczny rozwój - charakterystyka i pomiar [Posttraumatic growth - characteristic]. Psychiatria, 7, 129-142.

Park, C. L. (2009). Overview of theoretical perspectives. In C. L. Park, S. C. Lechner, M. H. Antoni, \& A. L. Stanton (Eds.), Medical illness and positive life change (pp. 11-31). Washington, DC: APA.

Ruini, C., \& Vescovelli, F. (2013). The role of gratitude in breast cancer: Its relationships with posttraumatic growth, psychological well-being and distress. Journal of Happiness Studies, 14, 263-274. https://doi.org/10.1007/s10902-012-9330-x

Schaefer, J. A., \& Moos, R. H. (2008). The context for posttraumatic growth: life crises, individual and social resources, and coping. In R. G. Tedeschi, C. L. Park, \& L. G. Calhoun (Eds.), Posttraumatic growth: Positive changes in aftermath of crisis (pp. 99-125). Mahwah, NJ: Lawrence Erlbaum Associates Publishers.

Shakespeare-Finch, J., \& de Dassel, T. (2009). Exploring posttraumatic outcomes as a function of childhood sexual abuse. Journal of Child Sexual Abuse, 18, 623640. https://doi.org/10.1080/10538710903317224

Shand, L. K., Cowlishaw, S., Brooker, J. E., Burney, S., \& Ricciardelli, L. A. (2015). Correlates of post-traumatic stress symptoms and growth in cancer patients: a systematic review and meta-analysis. Psycho-Oncology, 24, 624-634. https://doi.org/10.1002/ pon.3719

Stanton, A. L., Bower, J. E., \& Low, C. A. (2006). Posttraumatic growth in cancer. In G. Calhoun \& R. G. Tedeschi (Eds.), Handbook of posttraumatic growth: research and practice (pp. 138-176). Mahwah, NJ: Lawrence Erlbaum Associates Publishers.

Sumalla, E. C., Ochoa, C., \& Blanco, I. (2009). Posttraumatic growth in cancer: Reality or illusion? Clinical Psychology Review, 29, 24-33. https://doi. org/10.1016/j.cpr.2008.09.006
Tedeschi, R. G., \& Calhoun, L. G. (1996). The posttraumatic growth inventory: Measuring the positive legacy of trauma. Journal of Traumatic Stress, 9, 455-471. https://doi.org/10.1002/jts.2490090305

Tedeschi, R. G., Shakespeare-Finch, J., Taku, K., \& Calhoun, L. G. (2018). Posttraumatic Growth: Theory, Research, and Applications. New York: Routledge.

Tedeschi, R. G., Park, C., \& Calhoun, L. (1998). Posttraumatic growth: conceptual issues. In R. G. Tedeschi, C. R. Park, \& L. G. Calhoun (Eds.), Posttraumatic growth: Positive changes in the aftermath of crisis (pp. 1-22). Mahwah, NJ: Lawrence Erlbaum Associates Publishers.

Vollhardt, J. R. (2009). Altruism born of suffering and prosocial behaviour following adverse life events: A review and conceptualization. Social Justice $R e^{-}$ search, 22, 53-97. https://doi.org/10.1007/s11211009-0088-1

Zięba, M., Wiecheć, K., Biegańska-Banaś, J., \& Mieleszczenko-Kowszewicz, W. (2019). Coexistence of posttraumatic growth and post-traumatic depreciation in the aftermath of trauma: Qualitative and quantitative narrative analysis. Frontiers in Psychology, 10, 687. https://doi.org/10.3389/fpsyg.2019.00687

Zoellner, T., \& Maercker, A. (2006). Posttraumatic growth in clinical psychology - a critical review and introduction of a two component model. Clinical Psychology Review, 26, 626-653. https://doi. org/10.1016/j.cpr.2006.01.008 